\title{
Science Academies' Summer Research Fellowship Programme for Students and Teachers - 2016
}

\author{
Indian Academy of Sciences, Bengaluru \\ Indian National Science Academy, New Delhi \\ The National Academy of Sciences, India, Allahabad
}

The three national science academies offer several two-month Summer Fellowships to enable students/teachers (studying/teaching in India) to work with scientists associated with the three Academies during 2016. A copy of the application format, instructions to applicants including eligibility criteria, and a list of names of scientists/faculty who have consented to guide students/ teachers to work on short-term projects is displayed at the websites of the Academies [www.ias.ac.in; www.insaindia.org and www.nasi.org.in].

Applications are invited from interested students and teachers from all universities and colleges affiliated to UGC/AICTE/MCI/Accredited Institutions of State Universities for these Fellowships. The application should include: (a) filled up application form in the prescribed format; (b) scanned copies of marks sheets from class X till the last examination; (c) a write-up (in about 150-250 words) as to what the applicant would like to learn and achieve; (d) names of potential guides with whom the applicant would like to work. Student applicants should provide the email id of one of their teachers or HoD familiar with their work. The Academies will approach them for a recommendation letter in the prescribed format. The selected candidate should work with the assigned guide for two months any time during the calendar year, preferably during the summer.

Applications should be submitted by logging onto one of our websites given above. The registration number assigned soon after the online submission must be quoted in all future correspondence.

The last date for receipt of applications online is 30 November 2015.

Information of selection along with concurrence of the guide will be despatched around February-March 2016. The selected students/teachers will be provided appropriate round trip train fare and a monthly fellowship to meet their living expenses at the place of work.

Professor K.L. Sebastian Chairman, Joint Science Education Panel Indian Academy of Sciences, Bengaluru 